\title{
Initial experience of preoperative short-course radiotherapy followed by oxaliplatin-based consolidation chemotherapy for locally advanced rectal cancer
}

\section{Seung Ho Song}

Kyungpook National University

Jun Seok Park ( $\sim$ parkjs0802@knu.ac.kr)

Kyungpook National University School of Medicine https://orcid.org/0000-0001-5443-6748

Min Kyu Kang

Kyungpook National University

Gyu-Seog Choi

Kyungpook National University

Soo Yeun Park

Kyungpook National University

Hye Jin Kim

Kyungpook National University

Jong Gwang Kim

Kyungpook National University

Byung Woog Kang

Kyungpook National University

Jin Ho Baek

Kyungpook National University

Dong Won Baek

Kyungpook National University

Jae-Chul Kim

Kyungpook National University

Shin-Hyung Park

Kyungpook National University

Seung Hyun Cho

Kyungpook National University

An $\mathrm{Na}$ Seo

Kyungpook National University 


\section{Original Article}

Keywords: Rectal cancer, Short-course radiotherapy, consolidation chemotherapy, total mesorectal excision

Posted Date: January 29th, 2021

DOI: https://doi.org/10.21203/rs.3.rs-165028/v1

License: (c) (i) This work is licensed under a Creative Commons Attribution 4.0 International License. Read Full License

Version of Record: A version of this preprint was published at International Journal of Colorectal Disease on February 6th, 2021. See the published version at https://doi.org/10.1007/s00384-021-03875-0. 


\section{Abstract}

Purpose: We analyzed the safety and feasibility of preoperative short-course radiotherapy (SCRT) followed by consolidation chemotherapy for patients with locally advanced rectal cancer (LARC).

Methods: From April 2018 to May 2019, 19 patients with LACR were treated with SCRT followed by three cycles of consolidation chemotherapy with leucovorin, fluorouracil, and oxaliplatin (FOLFOX6) before surgery. Adjuvant chemotherapy relied on oxaliplatin. Tumor response, patient compliance, and toxicities were analyzed.

Results: The median age was 60 years (range 44-71), and 16 of the patients were male. The median tumor height was $5 \mathrm{~cm}$ (range 0-9) from anal verge. All patients received a total dose of $25 \mathrm{~Gy}$ in five fractions. The number of cycles of FOLFOX 6 before surgery was three in 17 , four in one, five in one. Five patients required dose reductions in consolidation chemotherapy. The median interval between initiation of SCRT and surgery was 10.6 weeks (range 8.6-16.4). A pathologic complete response was seen in two patients $(11 \%)$. Grade III toxicities to the preoperative treatment were seen in five patients $(26 \%)$ : diarrhea in two, a decreased white blood cell count in one, and anemia in two. Postoperative complications arising within 30 days developed in five patients (26\%). During the median follow-up period of 20.4 months, there was no tumor recurrence.

Conclusion: Preoperative SCRT followed by oxaliplatin-based consolidation chemotherapy showed acceptable toxicity and feasibility in patients with LARC. Prospective randomized trials are warranted to verify the efficacy and safety of this treatment strategy compared with conventional long-course concurrent chemoradiotherapy.

\section{Introduction}

Over several decades, innovative strategies have improved the oncologic outcomes of patients with rectal cancer [1], including standardization of total mesorectal excision (TME); preoperative chemoradiotherapy; diagnostic imaging, especially magnetic resonance imaging (MRI); and a multidisciplinary team (MDT) approach. These efforts have contributed to decrease local recurrence rates to around $5 \%$ of patients with locally advanced rectal cancer (LARC), as reported by some prospective studies $[2,3]$.

Widely used in most of the world, long-course concurrent chemoradiotherapy (LC-CCRT) has been accepted as a standard treatment modality for patients with LARC. This shows a downstaging effect on the tumors, high sphincter preservation, and low local recurrence rates. However, there are some concerns for patients' inconvenience, with high cost and frequent visits to hospital [4]. Moreover, there are also some concerns that about $25 \%-30 \%$ of patients suffer from distant metastases, even after neoadjuvant chemoradiation and TME followed by adjuvant chemotherapy [3, 5-7]. In our clinical setting, we commonly encounter patients with complex rectal cancers showing threatening circumferential margins and suspicious but invisible distant metastases such as aggressive extramural vascular invasions and high circulating levels of carcinoembryonic antigen (CEA), for whom both chemoradiation and 
chemotherapy are necessary. We hypothesized that short-course chemoradiotherapy (SCRT) with consolidation chemotherapy might achieve as effective local control of tumors as LC-CCRT, and could provide potential benefits including early eradication of micrometastases by consolidation chemotherapy within a similar time interval as surgery. Moreover, this approach might provide better compliance that cannot be met currently by LC-CCRT.

Herein, we report our initial experience of preoperative SCRT and consolidation chemotherapy for LARC to evaluate its safety and feasibility for future clinical application.

\section{Materials And Methods}

\section{Patients}

We reviewed our prospectively collected registry from April 2018 to May 2019 for patients with locally advanced rectal cancers who underwent SCRT followed by consolidation chemotherapy before surgery. The indications for SCRT and consolidation chemotherapy during the study period were as follows: (1) histologically confirmed rectal adenocarcinomas with the distal edge of the tumor located below the anterior peritoneal reflection (or $£ 10 \mathrm{~cm}$ from the anal verge); and (2) clinical stage T3-4 tumors or node positivity. Patients with MRI-detected extramural vascular invasion (mrEMVI) positivity or initial high CEA levels (> $7.0 \mathrm{ng} / \mathrm{mL}$ ) were also considered for SCRT and consolidation chemotherapy before surgery. Patients diagnosed with distant metastases were excluded. Treatment protocols for all patients were determined through the our MDT meeting. This study has been approved by the research ethics committee of Kyungpook National University Chilgok Hospital (KNUCH 2020-04-024).

\section{Treatment}

Patients received a total dose of $25 \mathrm{~Gy}$ in five fractions on consecutive days. After a 1-2-week rest period, patients then received three cycles of consolidation chemotherapy. We used a modified FOLFOX6 regimen: oxaliplatin $85 \mathrm{mg} / \mathrm{m}^{2}$ on day 1 ; leucovorin $400 \mathrm{mg}$ total dose over $2 \mathrm{~h}$ on day 1 ; fluorouracil 400 $\mathrm{mg} / \mathrm{m}^{2}$ bolus on day 1 ; followed by $2400 \mathrm{mg} / \mathrm{m}^{2}$ over $46 \mathrm{~h}$ (cycles repeated every 2 weeks). The interval between the last cycle of chemotherapy and surgery was 3-4 weeks (Figure 1).

We performed a high ligation of the inferior mesenteric artery, medial-to-lateral mobilization of the left colon, complete splenic flexure mobilization, and sharp pelvic dissection. If the tumor had invaded the external anal sphincter, we performed abdominoperineal resection [8]. We performed selective lateral pelvic lymph node dissection for patients with suspected metastatic lateral pelvic lymph nodes on initial imaging regardless of their response to neoadjuvant treatment [9]. About 2 weeks after surgery, we decided on adjuvant treatment for patients through our MDT meetings. The most common regimen was a modified FOLFOX6. Twelve cycles of chemotherapy were planned before and after surgery. The interval from surgery to initiation of adjuvant chemotherapy was usually 4 weeks.

\section{Evaluation}


Before neoadjuvant treatment, staging workups were performed on all patients. These involved taking a medical history; physical examinations including a digital rectal examination; laboratory tests; assays for CEA; colonoscopy; chest radiography; computed tomography (CT) scanning of the chest, abdomen and pelvis; and MRI scans. Restaging was done 6-7 weeks after completing radiotherapy by abdominal/pelvis/chest CT scans and pelvic MRI. MRI and CT examinations were assessed by a specialized radiologist who has more than 10 years of experience in interpreting colorectal cancer imaging. An instance of mrEMVI was defined as a serpiginous extension of a tumor signal within a vessel, defined as a tubular structure containing a signal void on T2-weighted images and shown in continuity on adjacent slices (Figure 2) [10,11]. A five-point MRI tumor regression grade (mrTRG) was used to report tumor response to neoadjuvant therapy [12]. The pathological stage was classified according to the TNM staging system of the American Joint Committee on Cancer, $7^{\text {th }}$ edition [13]. Regression of the primary tumor following neoadjuvant chemoradiation was assessed based on the tumor regression grade (TRG) as described by Rödel et al. [14]. Patients with a complete pathology response ( $\mathrm{pCR}$ ) were characterized as having no residual tumor cells within the rectal wall in surgical biopsy specimens. The circumferential resection margin (CRM) was defined as the closest distance from the outermost region with viable tumor cells to the resected specimen.

\section{Morbidity or toxicities}

The common terminology criteria for adverse events (version 5) were used for evaluating acute toxicities during the period from the initiation of radiation to surgery [7]. Postoperative morbidities within 30 days were graded according to the Clavien-Dindo classification [15].

\section{Statistical analysis}

Continuous variables are described as the mean and standard deviation or as the median and range. Categorical variables are described as frequencies and percentages. Times to events were measured from the initiation of radiotherapy and censored at the date of diagnosing any recurrence, or at the last outpatient clinic visit. All analyses were conducted using the R project for Statistical Computing, Version 4.0.1 (R Development Core Team, Vienna, Austria).

\section{Results}

Nineteen patients received sequential SCRT and FOLFOX6 therapy before surgery during the study period. Patient characteristics are summarized in Table 1. The median age of patients was 60 years (range 44$71)$, and 16 (84\%) of the patients were male. The median tumor distance from the anal verge was $5 \mathrm{~cm}$. Lower tumor distance $(£ 5 \mathrm{~cm})$, was seen in 11 patients $(58 \%)$. An initial high CEA level $(>7 \mathrm{ng} / \mathrm{mL})$ was seen in five patients. After SCRT and consolidation chemotherapy, such a high CEA level was seen in only one patient. A mrEMVI was seen in five and four patients in pre- and post-treatment MRI scans, respectively. In pre-treatment MRI, mesorectal fascia involvement was seen in nine patients. After SCRT 
and consolidation chemotherapy, mesorectal fascial involvement was seen in three patients in posttreatment MRI. A good response (mrTRG 1-3) was seen in 13 of the remaining 16 patients $(81 \%)$.

The median interval from completion of SCRT to initiation of chemotherapy was 10 days (range 4-24). The median interval from initiation of SCRT to surgery was 10.6 weeks (range 8.6-16.4). The median interval from completion of consolidation chemotherapy to surgery was 4.0 weeks (range 2.6-11.0).

All patients completed the planned schedule of SCRT without any interruption. Episodes of acute toxicity and the rate of adherence to the neoadjuvant treatment are listed in Table 2. Seventeen (90\%) of the 19 patients received three cycles of FOLFOX6. Consolidation chemotherapy dose reduction was observed in five patients: four suffered neutropenia and one experienced a chemoport infection.

Operative and postoperative complications are summarized in Table 3. One of the 19 patients preferred to undergo transanal endoscopic microsurgery at another hospital. Laparoscopic surgery was performed in 16 patients (84\%) and conversion to open surgery was needed in one patient because of an ischemic change in the splenic flexure of the colon. The median operative time was $250 \mathrm{~min}$. The protective stoma formation rate was 10/16 (63\%). At the close-out date for analysis, no patients had stomata except for two who underwent abdominoperineal resection. Three patients (15.8\%) exhibited lymph nodes larger than $5 \mathrm{~mm}$ in the short-axis diameter in the unilateral pelvic sidewall on the initial pelvic MRI. These patients underwent TME and lateral pelvic lymph node dissection. Two of those patients exhibited internal iliac lymph node metastasis, and one patient showed no lateral pelvic lymph node metastasis in the final pathologic reports. Postoperative complications occurred in five patients: one developed anastomotic leakage and was treated by rectal tube drainage without diversion of the stoma; one suffered atrial fibrillation at postoperative day 2 , and ileus and urinary retention at postoperative day 7 . This patient was diagnosed with anastomotic leakage with intra-abdominal fluid collection at postoperative day 9 and was then treated by percutaneous drainage without diversion of stoma. There was no mortality in the postoperative 30 days.

Pathology findings are summarized in Table 4. The pCR rate was 11\% (Supplemental Figures S1 and S2). Good tumor response (TRG 3 and 4) was seen in 17 patients (90\%). A pathological CRM-positive distance of $£ 1 \mathrm{~mm}$ was shown in two patients. These patients had a positive CRM in both pre- and post-treatment MRI scans.

Fifteen of the 19 patients (79\%) completed the planned 12 cycles of FOLFOX6 therapy. The other four patients discontinued for the following reasons. One patient received 10 cycles of FOLFOX 6 because of a urinary tract infection. Two patients stopped postoperative chemotherapy after nine and six cycles because of poor performance status and diarrhea. One patient refused further treatment after receiving four cycles of FOLFOX6. The actual delivered dose intensity was about $80 \%$ for both fluorouracil and oxaliplatin.

The median follow-up duration was 20.4 months (range 7.7-26.6). There was no tumor recurrence during this period. 


\section{Discussion}

The strategies for treating LARC usually involve a multidisciplinary approach. Radiation therapy might be one of the fundamental modalities in this. However, its role has been challenged in certain circumstances. Conventional LC-CCRT has led to low rates of local recurrence, but the incidence of distant metastases has not decreased as expected [3,5-7]. Some have attempted to find ways to achieve better results in the treatment of LARC [16-21], especially paying attention to preoperative consolidation or induction chemotherapy with chemoradiation to treat micrometastases early and with increased treatment compliance. Nonetheless, when applied with LC-CCRT, this approach raises a few concerns regarding the exceptionally long period of neoadjuvant treatment with a doubtful response in some patients. Therefore, when considering preoperative chemoradiation and chemotherapy, SCRT seems to be a good alternative because it can be completed within 1 week if equivalent oncologic outcomes are guaranteed compared with conventional LC-CCRT, as already reported by some groups [6, 7]. The waiting time from radiation to surgery could be a valuable period for consolidation chemotherapy to treat distant metastases. Accordingly, we conducted preoperative SCRT followed by three cycles of FOLFOX6 for patients with LARC, and our initial experience shows that it was safe and feasible.

Our indications for using SCRT followed by consolidation chemotherapy are different from those in other studies. The Polish II trial's eligibility criteria were cT4 or fixed cT3 lesion [7]. The CAO/ARO/AIO-12 trial included patients with cT3 or T4 rectal cancer [16]. During the study period in our study, the indications to adopt SCRT followed by consolidation chemotherapy focused on tumor characteristics suspicious of a high risk of systemic recurrence in preoperative evaluations, such as lymph node positivity or high CEA levels or adverse mrEMVI findings. Elevated CEA was associated with poor prognosis in colorectal cancer patients [22, 23]. Brown et al. reported that mrEMVI was a poor prognostic factor related to distant metastasis in patients with rectal cancer $[10,24]$. One of the crucial roles for SCRT and consolidation chemotherapy is efficient control of distant metastases in patients with LARC. Although this study was an initial one with a relatively short follow-up period (median 20.4 months), there has been no recurrence. Long-term follow-ups of our results are needed to clarify the clinical benefit of our strategy.

Our study did not include a totally neoadjuvant treatment scheme. Instead, we adhered to the treatment strategies for locally advanced rectal cancer, which comprise neoadjuvant treatment followed by curative surgery and adjuvant chemotherapy. In the CAO/ARO/AIO-12 trial, adjuvant chemotherapy was not recommended [16]. The experimental arm in the RAPIDO trial comprised full-dose chemotherapy before surgery, after SCRT, and without the adjuvant setting [18]. These trials reported a high rate of pathological complete response $(17 \%-28 \%)$ and high compliance with systemic therapy in the group that received totally neoadjuvant treatment $[16,18]$. Meanwhile, we chose three cycles of consolidation FOLFOX before surgery to make this similar to the conventional LC-CCRT. To provide personalized treatment, we planned the adjuvant chemotherapy after a MDT meeting that carefully reviewed the intraoperative findings and pathology reports for each patient. We attempt to reduce the need for unnecessary treatment, such as that given to patients who respond poorly to neoadjuvant treatment, and to avoid overadministration of chemotherapy in patients with low-risk disease. 
We found a pCR rate of $2 / 19(11 \%)$, slightly lower than in other trials with pCR rates of $\sim 15 \%[6,7,25]$. The reasons for this are unclear because this study was a small case series. However, there are two possible reasons. First, the interval from radiation to surgery might have been insufficient in our cohort, with a median time from initiating radiation to surgery of 10.6 weeks (range 8.6-16.4). In a Polish II trial, the median interval between the initiation of irradiation and surgery in the SCRT group was 12.4 weeks, and the PCR rate was $17 \%$ [7]. Second, in this study, we applied three cycles of FOLFOX6 before surgery. In a phase II nonrandomized trial, increasing cycles of FOLFOX6 after chemoradiation and before surgery were associated with a higher rate of $\mathrm{pCR}$ with better compliance to chemotherapy and without significant increase in postoperative complications [26]. In the RAPIDO trial, SCRT followed by 18 weeks of chemotherapy and TME achieved a pCR rate of $27.7 \%$ [18]. Therefore, here we prepared a prospective randomized trial comparing SCRT with LC-CCRT, considering the SCRT group to comprise four or more cycles of FOLFOX6 and increased the interval from radiation to surgery.

When adopting hypofractionated SCRT followed by consolidation chemotherapy before surgery for patients with LARC, treatment-related toxicities and postoperative complications are of concern compared with fully fractionated LC-CCRT. In terms of radiation- and chemotherapy-related toxicities, our results were similar to those of other studies. The incidence of grade 3 toxicity was $26 \%$ in our study. A German trial with LC-CCRT reported a $27 \%$ rate of grade 3-4 toxicities [5]. Another study reported that $27.1 \%$ of patients experienced grade 3-4 toxicities in the LC-CCRT treatment group [27]. In a recent two randomized trial, the rates of grade 3 or worse adverse events were $23-48 \%$ in a SCRT group and $21-25$ $\%$ in an LC-CCRT group $[7,18]$. The postoperative complication rate was also tolerable at $27 \%$. Grade 3 complication was observed in one patient (5.3\%). Other prospective studies with LC-CCRT reported postoperative morbidity rates of $25.0 \%$ to $36.0 \%[5,25,28]$. In a Polish II trial, the respective postoperative complication and grade $3-4$ complication rates were $19 \%$ and $8 \%$ in a SCRT group, and $21 \%$ and $6 \%$ in an LC-CCRT group [7].

MRI assessment of tumor downstaging might provide information on treatment response $[11,29,30]$. In our cohort, a good response ( $\mathrm{mrTRG} 1-3$ ) was seen in 13 of 16 patients (81\%). A retrospective study reported that $72.8 \%$ of patients showed good responses (mrTRG 1-3) after SCRT alone [30]. Here we conducted consolidation chemotherapy between radiation and surgery that might have influenced our results. However, the prognostic significance of the mrTRG system is controversial, and a prospective trial is ongoing to evaluate it $[17,31]$. Further studies are warranted to evaluate the efficacy of mrTRG in the context of SCRT and in real clinical practice.

There were some limitations to our study. First, it was a retrospective study in a single center. Second, we analyzed a small number of patients with a relatively short follow-up period, so late toxicities and longterm oncologic outcomes could not be evaluated. Moreover, discrepancies in the administered consolidation chemotherapy might have influenced our results. We have focused on the short-term outcomes of our strategy in this report. Based on these results, we expect that our proposed prospective multicenter randomized trial will clarify the safety and efficacy of SCRT followed by consolidation chemotherapy before surgery compared with LC-CCRT for patients with LARC. 
In conclusion, our initial experience of a short course of radiotherapy followed by oxaliplatin-based consolidation chemotherapy for patients with LARC has shown acceptable toxicity profiles and feasibility. Further large-scale and long-term results of our scheme will help test these conclusions.

\section{Declarations}

\section{Acknowledgements}

Funding: This work was supported by Biomedical Research Institute grant, Kyungpook National University Hospital (2020)

Author contributions: Seung Ho Song was responsible for writing of the manuscript; Min Kyu Kang and Seung Ho Song was responsible for analysis of the data; Jun Seok Park and Min Kyu Kang have contributed equally to the study as the corresponding authors. The study was proposed by Jun Seok Park and Min Kyu Kang. Data collection was done by Gyu-Seog Choi, Soo Yeun Park, Hye Jin Kim, Jong Gwang Kim, Byung Woog Kang, Jin Ho Baek, Dong Won Baek, Jae-Chul Kim, Shin-Hyung Park, Seung Hyun Cho, and An Na Seo.

Ethics approval: All patients provided informed consent, and this study was approved by the institutional review board (KNUCH 2020-04-024).

\section{Disclosure}

All authors have no conflicts of interest or financial ties to disclose.

\section{References}

1. Maehara Y, Soejima Y, Yoshizumi T, Kawahara N, Oki E, Saeki H, Akahoshi T, Ikegami T, Yamashita YI, Furuyama T, Sugimachi K, Harada N, Tagawa T, Harimoto N, Itoh S, Sonoda H, Ando K, Nakashima Y, Nagao Y, Yamashita N, Kasagi Y, Yukaya T, Kurihara T, Tsutsumi R, Takamori S, Sasaki S, Ikeda T, Yonemitsu Y, Fukuhara T, Kitao H, limori M, Kataoka Y, Wakasa T, Suzuki M, Teraishi K, Yoshida Y, Mori M (2019) The evolution of surgical treatment for gastrointestinal cancers. Int J Clin Oncol 24(11):1333-1349. doi: 10.1007/s10147-019-01499-7

2. Sebag-Montefiore D, Stephens RJ, Steele R, Monson J, Grieve R, Khanna S, Quirke P, Couture J, de Metz C, Myint AS, Bessell E, Griffiths G, Thompson LC, Parmar M (2009) Preoperative radiotherapy versus selective postoperative chemoradiotherapy in patients with rectal cancer (MRC CR07 and 
NCIC-CTG C016): a multicentre, randomised trial. Lancet 373(9666):811-20. doi: 10.1016/S01406736(09)60484-0

3. van Gijn W, Marijnen CA, Nagtegaal ID, Kranenbarg EM, Putter $H$, Wiggers T, Rutten HJ, Påhlman L, Glimelius B, van de Velde CJ; Dutch Colorectal Cancer Group (2011) Preoperative radiotherapy combined with total mesorectal excision for resectable rectal cancer: 12-year follow-up of the multicentre, randomised controlled TME trial. Lancet Oncol 12(6):575-82. doi: 10.1016/S14702045(11)70097-3

4. Kim JH (2017) Controversial issues in radiotherapy for rectal cancer: a systematic review. Radiat Oncol J 35(4):295-305. doi: 10.3857/roj.2017.00395

5. Sauer R, Becker H, Hohenberger W, Rödel C, Wittekind C, Fietkau R, Martus P, Tschmelitsch J, Hager E, Hess CF, Karstens JH, Liersch T, Schmidberger H, Raab R; German Rectal Cancer Study Group (2004) Preoperative versus postoperative chemoradiotherapy for rectal cancer. N Engl J Med 351(17):173140. doi: 10.1056/NEJMoa040694

6. Ngan SY, Burmeister B, Fisher RJ, Solomon M, Goldstein D, Joseph D, Ackland SP, Schache D, McClure B, McLachlan SA, McKendrick J, Leong T, Hartopeanu C, Zalcberg J, Mackay J (2012) Randomized trial of short-course radiotherapy versus long-course chemoradiation comparing rates of local recurrence in patients with T3 rectal cancer: Trans-Tasman Radiation Oncology Group trial 01.04. J Clin Oncol 30(31):3827-33. doi: 10.1200/JC0.2012.42.9597

7. Ciseł, B., Pietrzak, L., Michalski, W., Wyrwicz, L., Rutkowski, A., Kosakowska, E., Cencelewicz, A., Spałek, M., Polkowski, W., Jankiewicz, M., Styliński, R., Bębenek, M., Kapturkiewicz, B., Maciejczyk, A., Sadowski, J., Zygulska, J., Zegarski, W., Jankowski, M., Las-Jankowska, M., Toczko, Z., ... Polish Colorectal Study Group (2019). Long-course preoperative chemoradiation versus $5 \times 5$ Gy and consolidation chemotherapy for clinical T4 and fixed clinical T3 rectal cancer: long-term results of the randomized Polish II study. Annals of oncology : official journal of the European Society for Medical Oncology, 30(8), 1298-1303. doi: 10.1093/annonc/mdz186

8. Park JS, Park SY, Kim HJ, Cho SH, Kwak SG, Choi GS (2019) Long-term Oncologic Outcomes After Neoadjuvant Chemoradiation Followed by Intersphincteric Resection With Coloanal Anastomosis for Locally Advanced Low Rectal Cancer. Dis Colon Rectum 62(4):408-416. doi:

10.1097/DCR.0000000000001321

9. Kim, H. J., Choi, G. S., Park, J. S., Park, S. Y., Lee, H. J., Woo, I. T., \& Park, I. K. (2018). Selective lateral pelvic lymph node dissection: a comparative study of the robotic versus laparoscopic approach. Surgical endoscopy, 32(5), 2466-2473. doi: 10.1007/s00464-017-5948-4

10. Siddiqui MRS, Simillis C, Hunter C, Chand M, Bhoday J, Garant A, Vuong T, Artho G, Rasheed S, Tekkis P, Abulafi AM, Brown G (2017) A meta-analysis comparing the risk of metastases in patients with rectal cancer and MRI-detected extramural vascular invasion (mrEMVI) vs mrEMVI-negative cases. $\mathrm{Br}$ J Cancer 116(12):1513-1519. doi: 10.1038/bjc.2017.99

11. Brown G, Radcliffe AG, Newcombe RG, Dallimore NS, Bourne MW, Williams GT (2003) Preoperative assessment of prognostic factors in rectal cancer using high-resolution magnetic resonance 
imaging. Br J Surg 90(3):355-64. doi: 10.1002/bjs.4034

12. Patel UB, Taylor F, Blomqvist L, George C, Evans H, Tekkis P, Quirke P, Sebag-Montefiore D, Moran B, Heald R, Guthrie A, Bees N, Swift I, Pennert K, Brown G (2011) Magnetic resonance imaging-detected tumor response for locally advanced rectal cancer predicts survival outcomes: MERCURY experience. J Clin Oncol 29(28):3753-60. doi: 10.1200/JC0.2011.34.9068

13. Edge SB, Byrd DR, Compton CC (2011) AJCCCancer Staging Handbook in the AJCCCancer Staging Manual. 7th ed. New York, NY: Springer

14. Rödel C, Martus P, Papadoupolos T, Füzesi L, Klimpfinger M, Fietkau R, Liersch T, Hohenberger W, Raab R, Sauer R, Wittekind C (2005) Prognostic significance of tumor regression after preoperative chemoradiotherapy for rectal cancer. J Clin Oncol 23(34):8688-96. doi: 10.1200/JC0.2005.02.1329

15. Dindo D, Demartines N, Clavien PA (2004) Classification of surgical complications: a new proposal with evaluation in a cohort of 6336 patients and results of a survey. Ann Surg 240(2):205-13. doi: 10.1097/01.sla.0000133083.54934.ae

16. Fokas, E., Allgäuer, M., Polat, B., Klautke, G., Grabenbauer, G. G., Fietkau, R., Kuhnt, T., Staib, L., Brunner, T., Grosu, A. L., Schmiegel, W., Jacobasch, L., Weitz, J., Folprecht, G., Schlenska-Lange, A., Flentje, M., Germer, C. T., Grützmann, R., Schwarzbach, M., Paolucci, V., ... German Rectal Cancer Study Group (2019). Randomized Phase II Trial of Chemoradiotherapy Plus Induction or Consolidation Chemotherapy as Total Neoadjuvant Therapy for Locally Advanced Rectal Cancer: CAO/ARO/AIO-12. J Clin Oncol 37(34), 3212-3222. doi: 10.1200/JC0.19.00308

17. van der Valk MJM, Marijnen CAM, van Etten B, Dijkstra EA, Hilling DE, Kranenbarg EM, Putter $H$, Roodvoets AGH, Bahadoer RR, Fokstuen T, Ten Tije AJ, Capdevila J, Hendriks MP, Edhemovic I, Cervantes AMR, de Groot DJA, Nilsson PJ, Glimelius B, van de Velde CJH, Hospers GAP; Collaborative investigators (2020) Compliance and tolerability of short-course radiotherapy followed by preoperative chemotherapy and surgery for high-risk rectal cancer - Results of the international randomized RAPIDO-trial. Radiother Oncol 147:75-83. doi: 10.1016/j.radonc.2020.03.011

18. Bahadoer, R. R., Dijkstra, E. A., van Etten, B., Marijnen, C., Putter, H., Kranenbarg, E. M., Roodvoets, A., Nagtegaal, I. D., Beets-Tan, R., Blomqvist, L. K., Fokstuen, T., Ten Tije, A. J., Capdevila, J., Hendriks, M. P., Edhemovic, I., Cervantes, A., Nilsson, P. J., Glimelius, B., van de Velde, C., Hospers, G., ... RAPIDO collaborative investigators (2021). Short-course radiotherapy followed by chemotherapy before total mesorectal excision (TME) versus preoperative chemoradiotherapy, TME, and optional adjuvant chemotherapy in locally advanced rectal cancer (RAPIDO): a randomised, open-label, phase 3 trial. The Lancet. Oncology, 22(1), 29-42. doi: 10.1016/S1470-2045(20)30555-6

19. Battersby NJ, Dattani M, Rao S, Cunningham D, Tait D, Adams R, Moran BJ, Khakoo S, Tekkis P, Rasheed S, Mirnezami A, Quirke P, West NP, Nagtegaal I, Chong I, Sadanandam A, Valeri N, Thomas K, Frost M, Brown $G$ (2017) A rectal cancer feasibility study with an embedded phase III trial design assessing magnetic resonance tumour regression grade ( $\mathrm{mrTRG)}$ ) as a novel biomarker to stratify management by good and poor response to chemoradiotherapy (TRIGGER): study protocol for a randomised controlled trial. Trials 18(1):394. doi: 10.1186/s13063-017-2085-2 
20. Schrag D, Weiser MR, Goodman KA, Gonen M, Hollywood E, Cercek A, Reidy-Lagunes DL, Gollub MJ, Shia J, Guillem JG, Temple LK, Paty PB, Saltz LB (2014) Neoadjuvant chemotherapy without routine use of radiation therapy for patients with locally advanced rectal cancer: a pilot trial. $\mathrm{J}$ Clin Oncol 32(6):513-8. doi: 10.1200/JC0.2013.51.7904

21. Kim CW, Kang BM, Kim IY, Kim JY, Park SJ, Park WC, Bae KB, Bae BN, Baek SK, Baik SH, Son GM, Lee YS, Lee SH (2018) Korean Society of Coloproctology (KSCP) trial of cONsolidation Chemotherapy for Locally advanced mid or low rectal cancer after neoadjUvant concurrent chemoraDiothErapy: a multicenter, randomized controlled trial (KONCLUDE). BMC Cancer 18(1):538. doi: 10.1186/s12885018-4466-7

22. Park IJ, Choi GS, Lim KH, Kang BM, Jun SH (2009) Serum carcinoembryonic antigen monitoring after curative resection for colorectal cancer: clinical significance of the preoperative level. Ann Surg Oncol 16(11):3087-93. doi: 10.1245/s10434-009-0625-z

23. Chapman MA, Buckley D, Henson DB, Armitage NC (1998) Preoperative carcinoembryonic antigen is related to tumour stage and long-term survival in colorectal cancer. $\mathrm{Br} \mathrm{J}$ Cancer 78(10):1346-9. doi: 10.1038/bjc.1998.682

24. Chand M, Siddiqui MR, Swift I, Brown G (2016) Systematic review of prognostic importance of extramural venous invasion in rectal cancer. World J Gastroenterol 28;22(4):1721-6. doi: 10.3748/wjg.v22.i4.1721

25. Lefevre JH, Mineur L, Kotti S, Rullier E, Rouanet P, de Chaisemartin C, Meunier B, Mehrdad J, Cotte E, Desrame J, Karoui M, Benoist S, Kirzin S, Berger A, Panis Y, Piessen G, Saudemont A, Prudhomme M, Peschaud F, Dubois A, Loriau J, Tuech JJ, Meurette G, Lupinacci R, Goasgen N, Parc Y, Simon T, Tiret E (2016) Effect of Interval (7 or 11 weeks) Between Neoadjuvant Radiochemotherapy and Surgery on Complete Pathologic Response in Rectal Cancer: A Multicenter, Randomized, Controlled Trial (GRECCAR-6). J Clin Oncol 34(31):3773-3780. doi: 10.1200/JC0.2016.67.6049

26. Garcia-Aguilar J, Chow OS, Smith DD, Marcet JE, Cataldo PA, Varma MG, Kumar AS, Oommen S, Coutsoftides T, Hunt SR, Stamos MJ, Ternent CA, Herzig DO, Fichera A, Polite BN, Dietz DW, Patil S, Avila K; Timing of Rectal Cancer Response to Chemoradiation Consortium (2015) Effect of adding mFOLFOX6 after neoadjuvant chemoradiation in locally advanced rectal cancer: a multicentre, phase 2 trial. Lancet Oncol 16(8):957-66. doi: 10.1016/S1470-2045(15)00004-2

27. Ansari N, Solomon MJ, Fisher RJ, Mackay J, Burmeister B, Ackland S, Heriot A, Joseph D, McLachlan SA, McClure B, Ngan SY (2017) Acute Adverse Events and Postoperative Complications in a Randomized Trial of Preoperative Short-course Radiotherapy Versus Long-course Chemoradiotherapy for T3 Adenocarcinoma of the Rectum: Trans-Tasman Radiation Oncology Group Trial (TROG 01.04). Ann Surg 265(5):882-888. doi: 10.1097/SLA.0000000000001987

28. Roh MS, Colangelo LH, O'Connell MJ, Yothers G, Deutsch M, Allegra CJ, Kahlenberg MS, Baez-Diaz L, Ursiny CS, Petrelli NJ, Wolmark N (2009) Preoperative multimodality therapy improves disease-free survival in patients with carcinoma of the rectum: NSABP R-03. J Clin Oncol 27(31):5124-30. doi: $10.1200 /$ JCO.2009.22.0467 
29. Erlandsson J, Holm T, Pettersson D, Berglund Å, Cedermark B, Radu C, Johansson H, Machado M, Hjern F, Hallböök O, Syk I, Glimelius B, Martling A (2017) Optimal fractionation of preoperative radiotherapy and timing to surgery for rectal cancer (Stockholm III): a multicentre, randomised, nonblinded, phase 3, non-inferiority trial. Lancet Oncol 18(3):336-346. doi: 10.1016/S14702045(17)30086-4

30. Koëter T, van Elderen SGC, van Tilborg GFAJB, de Wilt JHW, Wasowicz DK, Rozema T, Zimmerman DDE (2020) MRI response rate after short-course radiotherapy on rectal cancer in the elderly comorbid patient: results from a retrospective cohort study. Radiat Oncol 15(1):53. doi: 10.1186/s13014-020-01500-y

31. Sclafani F, Brown G, Cunningham D, Wotherspoon A, Mendes LST, Balyasnikova S, Evans J, Peckitt C, Begum R, Tait D, Tabernero J, Glimelius B, Roselló S, Thomas J, Oates J, Chau I (2017) Comparison between MRI and pathology in the assessment of tumour regression grade in rectal cancer. $\mathrm{Br} J$ Cancer 117(10):1478-1485. doi: 10.1038/bjc.2017.320

\section{Tables}

Table 1. Patient characteristics 


\begin{tabular}{|c|c|}
\hline & $n=19$ \\
\hline Age, year & $60(44-71)$ \\
\hline \multicolumn{2}{|l|}{ Sex } \\
\hline Female & $3(15.8 \%)$ \\
\hline Male & $16(84.2 \%)$ \\
\hline \multicolumn{2}{|l|}{ ECOG PS } \\
\hline 0 & $2(10.5 \%)$ \\
\hline 1 & $17(89.5 \%)$ \\
\hline \multicolumn{2}{|l|}{ Clinical T stage } \\
\hline T3 & $13(68.4 \%)$ \\
\hline $\mathrm{T} 4$ & $6(31.6 \%)$ \\
\hline \multicolumn{2}{|l|}{ Clinical N stage } \\
\hline NO & $3(15.8 \%)$ \\
\hline $\mathrm{N}+$ & $16(84.2 \%)$ \\
\hline \multicolumn{2}{|l|}{ Differentiation } \\
\hline Well & $4(21.1 \%)$ \\
\hline Moderate & 15 (78.9\%) \\
\hline Tumor height, cm & $5(0-9)$ \\
\hline$\leq 5 \mathrm{~cm}$ & 11 (57.9\%) \\
\hline$>5 \mathrm{~cm}$ & 8 (42.1\%) \\
\hline CEA (pre-treatment), ng/mL & $3.1(0.8-53.4)$ \\
\hline Elevated (> $7.0 \mathrm{ng} / \mathrm{mL}$ ) & $5(26.3 \%)$ \\
\hline Normal (0 7.0 ng/mL) & $14(73.7 \%)$ \\
\hline CEA (post-treatment) $*, n g / m L$ & $2.1(0.7-7.6)$ \\
\hline Elevated (> 7.0 ng/mL) & $1(5.6 \%)$ \\
\hline Normal (0 7.0 ng/mL) & $17(94.4 \%)$ \\
\hline \multicolumn{2}{|l|}{ mrEMVI (pre-treatment) † } \\
\hline Positive & $5(29.4 \%)$ \\
\hline Negative & $12(70.6 \%)$ \\
\hline
\end{tabular}




\begin{tabular}{|ll|}
\hline & $n=19$ \\
\hline mrEMVI (post-treatment) $\ddagger$ & \\
\hline Positive & $4(25.0 \%)$ \\
\hline Negative & $12(75.0 \%)$ \\
\hline mrMRF (pre-treatment) $\dagger$ & \\
\hline Involved MRF $(<1 \mathrm{~mm})$ & $9(52.9 \%)$ \\
\hline Threatened MRF $(1-2 \mathrm{~mm})$ & - \\
\hline Clear MRF ( $\geq 2 \mathrm{~mm})$ & $8(47.1 \%)$ \\
\hline mrMRF (post-treatment) $¥$ & \\
\hline Involved MRF $(<1 \mathrm{~mm})$ & $3(18.8 \%)$ \\
\hline Threatened MRF (1-2 mm) & $1(6.2 \%)$ \\
\hline Clear MRF ( $\geq 2$ mm) & $12(75.0 \%)$ \\
\hline mrTRG $\ddagger$ & \\
\hline 2 (near complete regression) & $6(37.5 \%)$ \\
\hline 3 (moderate regression) & $7(43.7 \%)$ \\
\hline 4 (minimal regression) & $3(18.8 \%)$ \\
\hline
\end{tabular}

Abbreviations: ECOG PS, Eastern Cooperative Oncology Group performance status; CEA, carcinoembryonic antigen; mrEMVI, magnetic resonance imaging-detected extramural venous invasion; mrMRF, magnetic resonance mesorectal fascia status; mrTRG, magnetic resonance tumor regression grade.

Proportions are presented for categorical data and median with range for all continuous data.

* Exclude 1, no data

† One patient did not undertake an initial MRI, and one patient can not evaluate because of intussusception.

‡ Two patients did not undertake post-treatment MRI, and one patient undertake post-treatment MRI in another hospital.

Table 2. Acute toxicity to the neoadjuvant treatment 


\begin{tabular}{|ll|}
\hline \multicolumn{2}{|l|}{$\mathrm{n}=19$} \\
\hline Radiotherapy dose reduction and/or delay & 0 \\
\hline Number of cycles of consolidation chemotherapy & \\
\hline 3 & $17(89.5 \%)$ \\
\hline 4 & $1(5.3 \%)$ \\
\hline 5 & $1(5.3 \%)$ \\
\hline Consolidation chemotherapy dose reduction & $5(26.3 \%)$ \\
\hline Toxicity grade 1-2 & $14(73.7 \%)$ \\
\hline Diarrhea & 3 \\
\hline Anal pain & 4 \\
\hline Abdominal pain & 5 \\
\hline Anal hemorrhage & 2 \\
\hline White blood cell decreased & 13 \\
\hline Anemia & 13 \\
\hline Platelet count decreased & 4 \\
\hline Toxicity grade 3 & $5(26.3 \%)$ \\
\hline Diarrhea & 2 \\
\hline White blood cell decreased & 1 \\
\hline Anemia & 2 \\
\hline
\end{tabular}

Proportions are presented for categorical data

Table 3. Operative and postoperative outcomes within 30 days 


\begin{tabular}{|ll|}
\hline & $\mathrm{n}=19$ \\
\hline Type of operation & $12(63.2 \%)$ \\
\hline LAR & $4(21.1 \%)$ \\
\hline APR & $2(10.5 \%)$ \\
\hline TEM & $1(5.3 \%)$ \\
\hline Operative approach & \\
\hline Laparoscopic & $16(84.2 \%)$ \\
\hline Robotic & $2(10.5 \%)$ \\
\hline TEM & $1(5.3 \%)$ \\
\hline LPND & $3(15.8 \%)$ \\
\hline Open conversion & $1(5.3 \%)$ \\
\hline Operative time, min * & $250(100-400)$ \\
\hline Estimated blood loss, $\mathrm{mL} *$ & $50(10-300)$ \\
\hline Protective stoma + & $10 / 16(62.5 \%)$ \\
\hline Postoperative complication $\neq$ & $5(26.3 \%)$ \\
\hline Anastomotic leakage & 2 \\
\hline Ileus & 2 \\
\hline Urinary retention & 3 \\
\hline Atrial fibrillation & 1 \\
\hline Grade of complications, $\mathrm{n}(\%)$ & \\
\hline I-II & 6 \\
\hline III-IV & 2 \\
\hline Mortality & 0 \\
\hline
\end{tabular}

Abbreviations: LAR, low anterior resection; ISR, intersphincteric resection; APR, abdominoperineal resection; TEM, transanal endoscopic microsurgery; LPND, lateral pelvic lymph node dissection

Proportions are presented for categorical data and median with range for all continuous data.

* Exclude 1, no data 
† Exclude 3, TEM, and APR

‡ One patient has four complications (anastomotic leakage, ileus, urinary retention, and atrial fibrillation)

Table 4. Pathologic findings 


\begin{tabular}{|c|c|}
\hline & $n=19$ \\
\hline \multicolumn{2}{|l|}{ Pathologic $T$ category * } \\
\hline урто & $2(10.5 \%)$ \\
\hline урт2 & $7(36.8 \%)$ \\
\hline урТ3 & $8(42.1 \%)$ \\
\hline урт4b & $2(10.5 \%)$ \\
\hline \multicolumn{2}{|l|}{ Pathologic $\mathrm{N}$ category * } \\
\hline ypNO & $12(63.2 \%)$ \\
\hline ypN1 † & $5(26.3 \%)$ \\
\hline ypN2 & $1(5.3 \%)$ \\
\hline ypNx & $1(5.3 \%)$ \\
\hline \multicolumn{2}{|l|}{ Pathologic stage * } \\
\hline ypTONO & $1(5.3 \%)$ \\
\hline урт2Nx & $1(5.3 \%)$ \\
\hline 1 & $5(26.3 \%)$ \\
\hline IIA & $5(26.3 \%)$ \\
\hline IIC & $1(5.3 \%)$ \\
\hline IIIA & $2(10.5 \%)$ \\
\hline IIIB & $3(15.8 \%)$ \\
\hline IIIC & $1(5.3 \%)$ \\
\hline \multicolumn{2}{|l|}{ TRG } \\
\hline TRG 2 (moderate) & $2(10.5 \%)$ \\
\hline TRG 3 (good) & $15(78.9 \%)$ \\
\hline TRG 4 (complete) & $2(10.5 \%)$ \\
\hline \multicolumn{2}{|l|}{$\mathrm{CRM} \neq$} \\
\hline CRM negative (> $1 \mathrm{~mm}$ ) & $15(88.2 \%)$ \\
\hline CRM positive ( $\leq 1 \mathrm{~mm})$ & $2(11.8 \%)$ \\
\hline
\end{tabular}

Abbreviations: TRG, tumor regression grade; $\mathrm{CRM}$, Circumferential resection margin 
* The prescript " $y$ " used to indicate that the tumor had been treated before surgical resection.

† Two patients revealed internal iliac lymph node metastasis

‡ Exclude 2, no data

\section{Figures}


6-7
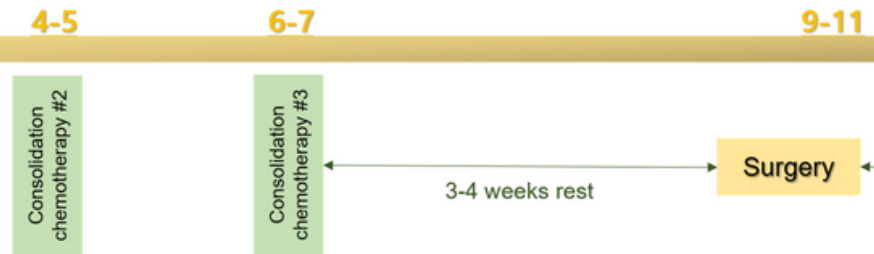

Surgery

3-4 weeks rest

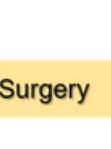

Chemotherapy: modified FOLFOX6

(Oxaliplatin $85 \mathrm{mg} / \mathrm{m}^{2}$ day 1 , leucovorin $400 \mathrm{mg} / \mathrm{m}^{2}$ total dose over two hours day 1 ,

fluorouracil $400 \mathrm{mg} / \mathrm{m}^{2}$ bolus day 1 , followed by $2400 \mathrm{mg} / \mathrm{m}^{2}$ over 46 hours, every 2 weeks)

\section{Figure 1}

Neoadjuvant treatment (short-course radiation followed by consolidation chemotherapy) protocol for patients with locally advanced rectal cancer in the study period 




Figure 2

Extramural venous invasion (arrow) in pre-treatment magnetic resonance imaging in patients with locally advanced rectal cancer

\section{Supplementary Files}

This is a list of supplementary files associated with this preprint. Click to download.

- FigureSupplementalFigureS1.docx

- FigureSupplementalFigureS2.docx 